
\title{
$\begin{array}{ll}\text { Research Square } & \text { They should not be considered conclusive, used to inform clinical practice, } \\ \text { or referenced by the media as validated information. }\end{array}$
}

\section{Comparison of The Peritoneal Dialysis and Continuous Veno-Venous Hemodiafiltration in 16 Neonates With Maple Syrup Urine Disease}

Ibrahim DEGER ( $\sim$ drdeger@gmail.com)

University of Dicle School of Medicine https://orcid.org/0000-0001-8093-5583

Muhittin Çelik

Gaziantep University: Gaziantep Universitesi

Ibrahim Taş

Zeynep Kamil Kadın ve Çocuk Hastalıkları Eğitim ve Araştırma Hastanesi: Zeynep Kamil Kadin ve Cocuk Hastaliklari Egitim ve Arastirma Hastanesi Serhat Samancı

Diyarbakır children hospital

\section{Research Article}

Keywords: CVVHDF, MSUD, Newborn, Peritoneal dialysis.

Posted Date: August 30th, 2021

DOI: https://doi.org/10.21203/rs.3.rs-780920/v1

License: (c) (i) This work is licensed under a Creative Commons Attribution 4.0 International License. Read Full License 


\begin{abstract}
Introduction: Continuous Renal Replacement Therapy (CRRT) is a well-known treatment modality for patients with acute renal failure and has been increasingly used for the treatment of metabolic disorders such as Maple Syrup Urine Disease (MSUD) in recent years. Herein, we aimed to discuss our experience in 16 newborn patients with MSUD who were treated with urgent renal replacement therapy (RRT).
\end{abstract}

Materials and Method: The data of patients who presented with an acute metabolic crisis due to Maple syrup urine disease and who were treated with RRT at Neonatal intensive care unit(NICU) between November 2016 and March 2020 were retrospectively evaluated. The patients underwent continuous veno-venous hemodiafiltration (CVVHDF) or peritoneal dialysis (PD) as renal replacement therapy.

Results: The study enrolled a total of 16 patients, of which 8 were male and 8 were female. Eleven (68.75\%) patients underwent CVVHDF and five (31.25\%) underwent peritoneal dialysis. The median post-treatment leucine level was 198(20-721) $\mu \mathrm{mol} / \mathrm{L}$ in the CVVHDF group and 1050(303-1653) $\mu \mathrm{mol} / \mathrm{L}$ in the PD group; the median leucine reduction rate per hour was $2.56 \%(1.75-7.6)$ in the CVVHDF group and $0.78 \%(0.54-1.83)$ in the PD group. There was a significant difference between both groups regarding both parameters $(p=0.08, p=0.001$, respectively). Complications such as hypotension, electrolyte imbalance, and filter obstruction occurred in the CVVHDF group while catheter revision was needed due to catheter obstruction in one patient in the PD group.

Conclusion: This study showed that CVVHDF is more effective than PD for rapidly eliminating elevated Leucine levels caused by MSUD in the newborn and it is not associated with increased complication rates.

\title{
What Is Known
}

Maple Syrup Urine Disease is one of the serious health problems in newborn babies. Peritoneal dialysis is frequently used. However, the use of Continuous veno-venous hemodiafiltration therapy is increasing steadily.

What is New: Leucine levels were more rapidly eliminated by the CVVHDF than PD and that CVVHDF did not increase mortality.

\section{Introduction}

Maple syrup urine disease (MSUD) is a congenital metabolic disease that results from the disordered metabolism of branched-chain amino acids(BCAA) valine, isoleucine, and leucine[1]. It is an autosomal recessive disorder that occurs due to the reduced activity of the branched-chain alpha-ketoacid dehydrogenase complex found in mitochondria[1]. Elevated serum levels of leucine and its metabolites impair brain development and growth, leading to neurological symptoms[2]. Leucine metabolites cause apoptosis in both glial and neuronal cells[2]. When the disease is suspected, plasma amino acids should be investigated to detect increased serum levels of branched-chain amino acids and isoleucine (a leucine metabolite) [3]. In children who have suspected disease due to family history or who undergo neonatal screening, appropriate nutritional management beginning in the first hours of life can prevent the development of neurological injury[3]. Early treatment is essential for preventing neurotoxicity and death[3]. The golden period for initiating therapy before irreversible neurological injury occurs is the first 7-10 days[3]. Renal replacement therapy (RRT) methods have been increasingly used for congenital metabolic disorders. The ultimate goal is to effectively remove toxic metabolites and to minimize the duration of exposure to those metabolites while the diagnostic studies are performed. Renal replacement therapy modalities include peritoneal dialysis (PD), intermittent hemodialysis (IHD) and continuous venovenous hemi filtration (CVVH), continuous veno-venous hemodialysis (CVVHD), and continuous veno-venous hemodiafiltration (CVVHDF) [4]. Among these, CVVHDF and PD are the most commonly used methods. Hemodiafiltration is the best method for removing toxic metabolites; however, peritoneal dialysis can also be utilized as an alternative in centers where hemodiafiltration cannot be performed[5].

The aim of the present study was to compare the effectiveness of CVVHDF and PD for acute detoxification in the newborn with MSUD.

\section{Materials And Method}

This study retrospectively evaluated the medical records of patients who were diagnosed with MSUD and treated with RRT at Diyarbakır Pediatric Hospital Neonatal Intensive Care Unit between 01 March 2016 and 20 March 2020.

\section{Study Inclusion Criteria:}

Patients admitted to and treated at the neonatal intensive care unit, who were:

Diagnosed with MSUD

Treated with RRT

Born at a gestational age of 37 to 42 weeks

Born with a birth weight of $\geq 2000 \mathrm{~g}$

Study Exclusion Criteria:

Infants with:

Multiple congenital anomalies 
Chromosomal disorders

Cyanotic congenital heart disease

Neural tube defects

Birthweight $<2000 \mathrm{~g}$

The medical records of infants with MSUD who had been admitted to the Neonatal Intensive Care Unit and treated with RRT during the specified time window were obtained. The medical data of the study patients were obtained from their medical records kept in the hospital's archive unit. A form was prepared for each case, which included the infants' demographic characteristics, birth weight, birth week, gender, length of hospital stay, RRT outcomes, as well as leucine, isoleucine, and valine levels and the other biochemical, hemogram, and coagulation parameters in the first 24 hours and during RRT.

\section{Catheterization}

Internal jugular or femoral veins were used for central venous catheterization (SVC). A 6.5-7 Fr (Arrow; Arrow International, Reading, Pennsylvania, USA) double-lumen hemodialysis catheter was used. During catheterization, asepsis criteria were complied with and sedoanalgesia was induced. Ultrasonography was used whenever necessary. The catheters were placed using the Seldinger Technique and fixed to the skin. Gambro Prismaflex device and HF20 filters (Baxter Healthcare, Deerfield, IL, USA) were used for hemodiafiltration in 11 patients. Five patients underwent peritoneal dialysis. Commercially produced standard solutions, dialysates, and replacement fluids were used. Standard solutions contained $5000 \mathrm{~mL}$ sterile water, $140 \mathrm{mmol} / \mathrm{L} \mathrm{sodium}, 2 \mathrm{mmol} / \mathrm{L}$ potassium, $1.75 \mathrm{mmol} / \mathrm{L}$ calcium, $111.5 \mathrm{mmol} / \mathrm{L}$ chloride, $32 \mathrm{mmol} / \mathrm{L}$ bicarbonate, and $6.1 \mathrm{mmol} / \mathrm{L}$ dextrose.

\section{Continuous Veno-Venous Hemodiafiltration}

The following CVVHDF settings were used: blood flow rate $10-20 \mathrm{~mL} / \mathrm{kg} / \mathrm{min}$, replacement flow rate $30-50 \mathrm{~mL} / \mathrm{kg} / \mathrm{hour}$, and dialysate flow rate 2000 $\mathrm{mL} / 1.73 \mathrm{~m}^{2} /$ hour. Anticoagulation was achieved by unfractionated heparin which was initially administered as a continuous infusion at a rate of 10 $\mathrm{IU} / \mathrm{kg} /$ hour and then adjusted to an aPTT (activated partial thromboplastin time) of 60-80 seconds during follow-up. The goal was to keep aPTT 1.5 times normal. When aPTT was 2 times normal, heparin dosage was reduced. Blood samples were collected from all patients every 4 hours to check blood gases, electrolytes, PT, and aPTT. Blood amino acid levels were checked every 12 hours. Serum phosphorus level of less than $4 \mathrm{mg} / \mathrm{dL}$ was considered hypophosphatemia. Serum corrected calcium level of less than $8 \mathrm{mg} / \mathrm{dL}$ was considered hypocalcemia. Patients who developed hypophosphatemia and hypocalcemia were administered intravenous phosphorus and calcium supplementation. It was attempted to keep serum calcium level at $8-11 \mathrm{mg} / \mathrm{dL}$ and serum phosphorus level at $4-8 \mathrm{mg} / \mathrm{dL}$. Patients who developed hypotension after the initiation of CVVHDF were begun on inotropes and their dosage was increased as needed.

\section{Peritoneal Dialysis}

Peritoneal dialysis catheter (single cuff Tenckhoff catheter) was placed by a pediatric urologist $3-5 \mathrm{~cm}$ below the umbilicus under local anesthesia at the bedside. Peritoneal dialysis was performed in 30-60-minute (intermittent) cycles using the Baxter dialysis system. Dialysis was carried out using filling volumes of $10-20 \mathrm{~mL} / \mathrm{kg}$ on the first day, which were increased to $30 \mathrm{~mL} / \mathrm{kg}$ on the second day. The fluid amounts that were introduced and removed were recorded for each cycle. The patients were provided with hypercaloric parenteral nutrition (110-130 kcal/kg/day) and oral thiamin supplementation (10 $\mathrm{mg} / \mathrm{kg} /$ day) via an orogastric catheter. Intravenous fluids containing a high amount of dextrose (rate 10-12 mg/ $\mathrm{kg} / \mathrm{min}$ ) and intravenous lipid emulsions (rate $1-2 \mathrm{~g} / \mathrm{kg} /$ day) were commenced to reach an anabolic state. In MSUD, renal replacement therapy was started when the patients developed coma, gastrointestinal intolerance, worsening clinical condition, inability to feed, and a plasma leucine level of $\geq 1700 \mu \mathrm{mol} / \mathrm{L}$ after a 4 -hour medical treatment. When plasma leucine level dropped below $1000 \mu \mathrm{mol} / \mathrm{L}$, renal replacement therapy was stopped.

\section{Calculations}

At the end of the renal replacement therapy, the Leucine reduction rate percentage achieved was calculated according to the formula: (pre-treatment leucine post-treatment leucine/pre-treatment leucine) $\times 100[6]$.

Leucine reduction rate percentage per hour was calculated according to the formula: leucine reduction rate percentage achieved/treatment hours[7].

The study was approved by Dicle University Ethics Committee (03.06.2021/314).

\section{Statistical Analyses}

Study data were analyzed using SPSS statistical software package. Quantitative variables were presented as median (minimum-maximum) and categoric variables as number (n) and percentage (\%). Since the parametric test assumptions were not met, the Mann-Whitney $U$ test was used to compare the means of two independent groups. A p-value of less than 0.05 was considered statistically significant.

\section{Results}

Eight (50\%) patients were female and 8 (50\%) were male. Eleven (68.75\%) patients underwent CVVHDF and 5 (31.25\%) underwent peritoneal dialysis. The median age was 13 (7-28) days in the CVVHDF group and 9 (7-28) days in the PD group. The median weight on admission was $3370 \mathrm{~g}(2750-3930) \mathrm{g}$ in the CVVHDF group and $3000(2150-3780) \mathrm{g}$ in the PD group. The median gestational week was 39 (37-42) weeks in the CVVHDF group and 40 (39-41) weeks in the PD group. The demographic characteristics and treatment options were shown in Table 1; the comparison of the means of continuous variables by treatment modality was shown in Table 2 and Figs. 1, 2, and 3. According to the comparison of the means of continuous variables by treatment modality, 
there was a significant difference between the CVVHDF and PD groups with respect to mean dialysis duration, post-treatment leucine level, and leucine reduction rate per hour $(p<0.05)$ whereas no significant difference was found regarding the pre-treatment leucine level and leucine reduction rate $(p>0.05)$. Among 10 (90\%) patients who underwent CVVHDF, the right internal jugular vein was used as the catheter entry site in seven patients, the left internal jugular vein in 3 patients, and the right femoral vein in $1(10 \%)$ patient. Hypotension was defined as a drop of $>20$ mmHg in mean arterial pressure compared to baseline or a mean arterial pressure below 3 percentiles by gestational week. Six (54.5\%) patients received inotropic support prior to CVVHDF due to hypotension. Filter replacement was performed in $2(18 \%)$ patients due to filter obstruction. Hypothermia was defined as a body temperature of less than $36.50 \mathrm{C}$; one patient who underwent CVVHDF developed hypothermia, whose incubator temperature was increased and normothermia was achieved.

\section{Discussion}

This study enrolled patients who underwent peritoneal dialysis or CVVHDF as a CRRT method. As far as we know, our study is the largest newborn study to date that compared the PD and CVVHDF methods in MSUD. Our results indicated that leucine levels were more rapidly eliminated by the CVVHDF than PD and that CVVHDF did not increase mortality.

Maple syrup urine disease presents with coma in the newborn period; accumulation of toxic metabolites, especially leucine and its metabolites, causes acute metabolic crisis, severe neurological and developmental injury, or even death[1, 8]. It has been shown that cerebral leucine accumulation causes neurotransmitter consumption and replaces other essential amino acids, leading to impaired normal brain growth and development; thus, its levels should be effectively lowered as quickly as possible[9]. Patients may present with inability to suck, poor feeding, intolerance to feeding, vomiting, hypotonia, apnea, respiratory failure, and convulsions[4, 5]. Infants with MSUD are at risk of metabolic decompensation and should be treated with an emergency protocol[9]. The goal of acute therapy is to reduce catabolism and to increase protein anabolism[9]. Severe cases should be aggressively treated (e.g. dialysis, hemofiltration, parenteral feeding, and/or orogastric feeding) [9]. The acute dietary therapy should be aggressive and contain adequate energy (up to $150 \%$ of normal energy expenditure) provided by a formula, which is free of BCAA, and fluids]. ${ }^{9}$ The most common cause of admission among our patients was feeding problems and respiratory failure. In these patients, as the leucine reduction rate per hour increases, the time to starting complete enteral feeding decreases.

Lowering the concentrations of BCAA and their metabolites can prevent neurological injury and save lives[5]. Patients need a rapid diagnosis and urgent elimination of toxins with specific therapy[1]. In recent years, recommendations about the use of CVVHDF have been increasing thanks to technological advances and to an increasing, albeit still limited, number of case reports discussing the CRRT methods $[5,7,10]$. Renal replacement therapies have been successfully used to lower the plasma levels of low molecular weight substances[7]. While peritoneal dialysis has been frequently used in the newborn, the rate of using intermittent hemodialysis (IHD) and continuous hemofiltration methods has been constantly rising[7, 10]. In newborn babies, it may be difficult to perform CRRT due to difficulties related to catheter placement and hemodynamic instability[10]. In our unit, five patients with a failed catheter placement attempt had to undergo PD. Peritoneal dialysis has a limited capacity to increase renal clearance and to remove the solute burden and fluid overload, which makes CRRT a more favorable method[7]. Phan et al[7]. showed the efficacy of IHD in acute MSUD crisis in children. However, IHD may lead to a greater rate of hemodynamic instability $[7,8,10]$. Arterial blood pressure and cerebral blood flow disorders may increase the extent of neurological injury[7, 8, 10]. Newborn infants are more susceptible to this side effect[10]. In MSUD, leucine levels may increase if the catabolic process persists or when they show a rebound increase after $\operatorname{IHD}[5,7,10]$. It is believed that thanks to allowing a safer electrolyte replacement and a lower risk of rebound leucine increase, CVVD, CVVHD, and CVVHDF, among other continuous modalities, may offer an advantage over IHD[7, 10, 12, 13]. There has been a recent increase in the number of studies that dealt with the technique and frequency of RRT [5, 10-12]. Studies on patients with congenital metabolic disorders have shown that CVVHDF was effective and provided a rapid reduction in toxic metabolites[1, 14]. Jouvet et al[15]. compared the three methods (CVVHDF, CVVH, and CVVHD) in three infants with MSUD and demonstrated that CVVHDF was more effective in eliminating leucine. Kornecki et al[16]. showed that leucine levels more rapidly fell with CVVHDF compared with CVVH. Çelik et al[5]. reported that the short-term outcomes of patients with MSUD were favorable with both dialysis methods, although longer leucine exposure with PD may increase the risk of irreversible brain injury. There are a limited number of studies, mostly in the form of case reports, examining acute detoxification therapy in newborn infants with $\operatorname{MSUD}[5,10,15]$.

Since leucine is not an osmotic molecule, its rapid removal does not cause any problem; furthermore, since brain blood flow is constant, there is no risk of brain edema[10]. However, CRRTs are associated with several complications. Previous studies have widely reported a number of complications in patients treated with CVVHDF, particularly in the newborn, such as serum electrolyte abnormalities, hemodynamic instability, hemorrhage, and catheter obstruction[17, 18]. In our study, 11 (68.75\%) patients received mechanical ventilation support. Hypotension, filter obstruction, and some serum electrolyte abnormalities were the most common complications in our study. Six of 11 patients who underwent CVVHDF developed hypotension, three patients hypokalemia, one patient hypothermia, and two patients filter obstruction in dialysis set, while one patient underwent SVC replacement due to catheter obstruction. A patient in the PD group underwent catheter revision due to obstruction. Eight (72.7\%) patients in the CVVHDF group and 3 (60\%) in the PD group received mechanical ventilation support. Our study did not find any significant difference between the CVVHDF and PD groups with regard to the leucine reduction rate. However, the leucine reduction rate per hour was significantly higher in the CVVHDF group than in the PD group $(p<0.05)$. These results indicate that CVVHDF is much more effective than PD in newborn MSUD patients. However, one must exercise caution about hypotension and electrolyte imbalance; additionally, when a patient develops hypothermia, body temperature should be carefully observed. One of our patients died in the second week after RRT.

\section{Limitations}

Our study had some limitations. Firstly, it was a single-center study with a limited number of patients. Secondly, patients treated with HDF were treated only with the CVVHDF method. We could not compare the effectiveness of different treatment methods. Thirdly, there may have been some errors related to data accessibility and collection owing to the retrospective nature of the study. As a final limitation, long-term outcomes could not be assessed due to the inability 
to reach the surviving patients. Despite these limitations, we believe that this study contributed to the literature about the treatment of newborn infants with MSUD.

\section{Conclusion}

In conclusion, we believe that CVVHDF is the most effective treatment method for the treatment of acute metabolic crisis of MSUD in the newborn period when used in conjunction with nutritional support and general medical therapies. Continuous veno-venous hemodiafiltration rapidly and safely eliminates leucine levels. Still, caution should be exercised about several complications of the method during its use, such as hemodynamic instability, electrolyte imbalance, hypothermia and filter obstruction. There is a need for comprehensive studies involving larger patient populations in order to implement this method as a standard protocol.

\section{List Of Abbreviations}

\section{CRRT}

Continuous Renal Replacement Therapy, MSUD; Maple Syrup Urine Disease, RRT; Renal replacement therapy, NICU; Neonatal intensive care unit, CVVHDF; Continuous veno-venous hemodiafiltration, PD; Peritoneal dialysis.

\section{Declarations}

\section{Compliance with Ethical Standards}

\section{Funding: N/A}

\section{Conflict of interests/Competing interests: N/A}

Ethical approval and consent to participate: Our study received ethics approval from the Dicle University Medical Faculty non-interventional clinical studies ethics committee, Diyarbakır, Turkey (03 June 2021/314).

\section{Consent for publication: N/A}

\section{Availability of data and material: N/A}

Code availability: N/A

Disclaimer: N/A

Authors' contributions: All authors fulfil the criteria for authorship; I.D, M.Ç and I.T. initiated the study; I.D, M.Ç and I.T. Collected the data; I.D, M.Ç and S.S. analysed the data; I.D and M.Ç. Interpreted the data; I.D, M.Ç, S.S and I.T.drafted the report. All authors commented on the drafts and have seen and approved the final version.

\section{References}

1. Stroek K, Boelen A, Bouva MJ, De Sain-van der Velden M, Schielen PCJI, Maase R et al (2020 May) Evaluation of 11 years of newborn screening for maple syrup urine disease in the Netherlands and a systematic review of the literature: Strategies for optimization. JIMD Rep 13(1):68-78 54(

2. Frazier DM, Allgeier C, Homer C, Marriage BJ, Ogata B, Rohr F et al (2014 Jul) Nutrition management guideline for maple syrup urine disease: an evidenceand consensus-based approach. Mol Genet Metab 112(3):210-217

3. Strauss KA, Puffenberger EG, Carson VJ (2006) Maple Syrup Urine Disease. Jan 30 [updated 2020 Apr 23]. In: Adam MP, Ardinger HH, Pagon RA, Wallace SE, Bean LJH, Stephens K, Amemiya A, editors. GeneReviews ${ }^{\circledR}$ [Internet]. Seattle (WA): University of Washington, Seattle; 1993-2020. PMID: 20301495

4. Demirkol D, Şık G, Topal N, Çıtak A, Zeybek Ç, Tüten A, Bilge I (2016) Continuous venovenous hemodiafiltration in the treatment of maple syrup urine disease. Blood purification 42(1):27-32

5. Celik M, Akdeniz O, Ozgun N, Ipek MS, Ozbek MN (2019 Jun) Short-term results of continuous venovenous haemodiafiltration versus peritoneal dialysis in 40 neonates with inborn errors of metabolism. Eur J Pediatr 178(6):829-836

6. Puliyanda DP, Harmon WE, Peterschmitt MJ, Irons M, Somers MJ (2002) Utility of hemodialysis in maple syrup urine disease. Pediatr Nephrol 17:239-242

7. Phan V, Clermont MJ, Merouani A, Litalien C, Tucci M, Lambert M, Mitchell G (2006) Jouvet P:Duration of extracorporeal therapy in acute maple syrup urine disease: a kinetic model. Pediatr Nephrol 21:698-704

8. Zinnanti WJ, Lazovic J, Griffin K, Skvorak KJ, Paul HS, Homanics GE et al (2009 Apr) Dual mechanism of brain injury and novel treatment strategy in maple syrup urine disease. Brain 132(Pt 4):903-918

9. Strauss KA, Carson VJ, Soltys K, Young ME, Bowser LE, Puffenberger EG et al (2020 Mar) Branched-chain a-ketoacid dehydrogenase deficiency (maple syrup urine disease): Treatment, biomarkers, and outcomes. Mol Genet Metab 129(3):193-206

10. Aygün F, Kıykım E, Aktuğlu-Zeybek Ç, Zubarioğlu T, Cam H (2019) Treatment of maple syrup urine disease with high flow hemodialysis in a neonate. Turk J Pediatr 61(1):107-110

11. Spinale JM, Laskin BL, Sondheimer N, Swartz SJ, Goldstein SL (2013) High-dose continuous renal replacement therapy for neonatal hyperammonemia. Pediatric Nephrology 28(6):983-986 
12. Akduman H, Okulu E, Eminoğlu FT, Kendirli T, Tunç G, Azapağası E et al. Continuous venovenous hemodiafiltration in the treatment of newborns with an inborn metabolic disease: a single center experience. Turk J Med Sci. 2020 Feb 13;50(1):12-17

13. Bojan M, Gioanni S, Vouhé PR, Journois D, Pouard P (2012 Aug) Early initiation of peritoneal dialysis in neonates and infants with acute kidney injury following cardiac surgery is associated with a significant decrease in mortality. Kidney Int 82(4):474-481

14. Quan A, Quigley R (2005 Apr) Renal replacement therapy and acute renal failure. Curr Opin Pediatr 17(2):205-209

15. Jouvet P, Poggi F, Rabier D, Michel JL, Hubert P, Sposito M et al (1997) Continuous venovenous haemodiafiltration in the acute phase of neonatal maple syrup urine disease. J Inherit Metab Dis 20:463-472

16. Kornecki A, Tauman R, Lubetzki R, Lubetzky R, Sivan Y (2002) Continuous renal replacement therapy for non-renal indications: experience in children. Isr Med Assoc J 4:345-348

17. Arbeiter AK, Kranz B, Wingen AM, Bonzel KE, Dohna-Schwake C, Hanssler L et al. 2010 Continuous venovenous haemodialysis (CVVHD) and continuous peritoneal dialysis (CPD) in the acute management of 21 children with inborn errors of metabolism. Nephrol Dial Transplant 25:1257-1265

18. Sohn YB, Paik KH, Cho HY, Kim SJ, Park SW, Kim ES et al (2012) Continuous renal replacement therapy in neonates weighing less than 3 kg. Korean J Pediatr 55:286-292

\section{Tables}


Table 1

The demographic and clinical characteristics of the patients

\begin{tabular}{|c|c|c|c|c|c|c|c|c|c|c|c|c|}
\hline Patient & Sex & $\begin{array}{l}\text { Weight at } \\
\text { admission } \\
\text { (gram) }\end{array}$ & $\begin{array}{l}\text { Age at } \\
\text { admission } \\
\text { (days) }\end{array}$ & $\begin{array}{l}\text { RRT } \\
\text { modality }\end{array}$ & $\begin{array}{l}\text { Dialysis } \\
\text { time } \\
\text { (hour) }\end{array}$ & $\begin{array}{l}\text { Initial } \\
\text { plasma } \\
\text { leucine } \\
(\mu \mathrm{mol} / \mathrm{L})\end{array}$ & $\begin{array}{l}\text { Final } \\
\text { plasma } \\
\text { leucine } \\
(\mu \mathrm{mol} / \mathrm{L})\end{array}$ & Complication & İntubation & $\begin{array}{l}\text { Leucine } \\
\text { reduction } \\
\text { rate \% } \\
\text { achieved }\end{array}$ & $\begin{array}{l}\text { Leucine } \\
\text { reduction } \\
\text { rate \% } \\
\text { per hour }\end{array}$ & $\begin{array}{l}\text { Syl } \\
\text { at } \\
\text { ad } 1\end{array}$ \\
\hline 1 & Female & 3600 & 10 & CVVHDF & 24 & 5796 & 482 & No & Yes & 91.6 & 3.8 & $\begin{array}{l}\text { Po } \\
\text { fe } \\
\text { vor } \\
\text { res } \\
\text { fai }\end{array}$ \\
\hline 2 & Male & 3380 & 20 & CVVHDF & 12 & 2300 & 190 & No & Yes & 91.7 & 7.6 & $\begin{array}{l}\text { Co } \\
\text { vor } \\
\text { res } \\
\text { fai }\end{array}$ \\
\hline 3 & Female & 2900 & 28 & CVVHDF & 24 & 1736 & 154 & No & Yes & 91.1 & 3.79 & $\begin{array}{l}\text { Po } \\
\text { fee } \\
\text { vol } \\
\text { res } \\
\text { fai }\end{array}$ \\
\hline 4 & Female & 3200 & 25 & CVVHDF & 36 & 2540 & 198 & No & Yes & 92.2 & 2.56 & $\begin{array}{l}\text { Vo } \\
\text { res } \\
\text { fai }\end{array}$ \\
\hline 5 & Female & 2950 & 7 & CVVHDF & 36 & 2233 & 345 & $\begin{array}{l}\text { Filter } \\
\text { blockage }\end{array}$ & No & 84.5 & 2.34 & $\begin{array}{l}\text { Co } \\
\text { vor }\end{array}$ \\
\hline 6 & Male & 3930 & 23 & CVVHDF & 36 & 3758 & 156 & No & Yes & 95.8 & 2.66 & $\begin{array}{l}\text { Re: } \\
\text { fai }\end{array}$ \\
\hline 7 & Female & 3800 & 11 & CVVHDF & 48 & 4561 & 721 & CVC revision & No & 84.1 & 1.75 & $\begin{array}{l}\text { Co } \\
\text { vor } \\
\text { por }\end{array}$ \\
\hline 8 & Male & 3900 & 9 & CVVHDF & 36 & 3600 & 270 & No & No & 92.5 & 2.56 & $\begin{array}{l}\text { Po: } \\
\text { fe } \epsilon \\
\text { vor }\end{array}$ \\
\hline 9 & Male & 3000 & 12 & CVVHDF & 48 & 3000 & 176 & Hypothermia & Yes & 94.1 & 1.96 & $\begin{array}{l}\text { Re! } \\
\text { fai } \\
\text { vol }\end{array}$ \\
\hline 10 & Female & 2750 & 13 & CVVHDF & 48 & 3767 & 20 & $\begin{array}{l}\text { Filter } \\
\text { blockage }\end{array}$ & Yes & 99.4 & 2.07 & $\begin{array}{l}\text { Re: } \\
\text { fai } \\
\text { vor }\end{array}$ \\
\hline 11 & Female & 3670 & 15 & CVVHDF & 24 & 2430 & 422 & No & Yes & 82.6 & 3.44 & $\begin{array}{l}\text { Re: } \\
\text { fai } \\
\text { fee }\end{array}$ \\
\hline 12 & Male & 3780 & 7 & PD & 48 & 2600 & 303 & No & No & 88.3 & 1.83 & $\begin{array}{l}\text { Po: } \\
\text { fee } \\
\text { vol }\end{array}$ \\
\hline 13 & Female & 2150 & 9 & PD & 72 & 2440 & 600 & No & Yes & 75.4 & 1.04 & $\begin{array}{l}\text { Po } \\
\text { fee } \\
\text { res } \\
\text { fai }\end{array}$ \\
\hline 14 & Male & 3600 & 10 & PD & 156 & 4667 & 675 & No & Yes & 85.5 & 0.54 & $\begin{array}{l}\text { Po } \\
\text { fe } \\
\text { vor } \\
\text { res } \\
\text { fai }\end{array}$ \\
\hline 15 & Male & 2800 & 8 & PD & 135 & 3600 & 967 & $\begin{array}{l}\text { Blockage, } \\
\text { revision }\end{array}$ & No & 73.1 & 0.54 & $\begin{array}{l}\text { Pol } \\
\text { fe } \\
\text { vol } \\
\text { cor }\end{array}$ \\
\hline 16 & Male & 3000 & 28 & PD & 120 & 4115 & 250 & No & Yes & 93.9 & 0.78 & $\begin{array}{l}\text { Po } \\
\text { fe } \\
\text { vol } \\
\text { res } \\
\text { fai }\end{array}$ \\
\hline
\end{tabular}

CVC: Central venous catheter, CVVHDF: Continuous veno-venous hemodiafiltration, MV: Mechanical ventilation, PD: peritoneal dialysis, RRT: Renal replaceme therapy. 
Table 2

Comparison of means of continuous variables according to treatment modalities

\begin{tabular}{|c|c|c|c|c|c|c|c|}
\hline & \multicolumn{7}{|c|}{ Renal Replacement Therapy method } \\
\hline & \multicolumn{3}{|c|}{ CVVHDF $(n=11)$} & \multicolumn{4}{|c|}{$\mathrm{PD}(\mathrm{n}=5)$} \\
\hline & $\begin{array}{l}\text { Mean } \\
\text { Rank }\end{array}$ & $\begin{array}{l}\text { Sum of } \\
\text { Ranks }\end{array}$ & $\begin{array}{l}\text { median(minimum- } \\
\text { maximum) }\end{array}$ & $\begin{array}{l}\text { Mean } \\
\text { Rank }\end{array}$ & $\begin{array}{l}\text { Sum of } \\
\text { Ranks }\end{array}$ & $\begin{array}{l}\text { median(minimum- } \\
\text { maximum) }\end{array}$ & $p^{*}$ \\
\hline Dialysis time (hour) & 6.14 & 67.50 & $36(12-48)$ & 13.70 & 68.50 & $120(48-56)$ & 0.01 \\
\hline $\begin{array}{l}\text { Pretreatment plasma leucine levels } \\
(\mu \mathrm{mol} / \mathrm{L})\end{array}$ & 7.86 & 86.50 & $3000(1736-5796)$ & 9.90 & 49.50 & $3600(2440-4667)$ & 0.42 \\
\hline $\begin{array}{l}\text { Posttreatment plasma leucine levels } \\
(\mu \mathrm{mol} / \mathrm{L})\end{array}$ & 7.00 & 77.00 & 198(20-721) & 11.80 & 59.00 & $600(250-967)$ & 0.08 \\
\hline Leucine reduction rate $\%$ achieved & 9.73 & 107.00 & $91.7(82.6-99.4)$ & 5.80 & 29.00 & $85.5(73.1-93.9)$ & 0.12 \\
\hline Leucine reduction rate $\%$ per hour & 11 & 10.91 & $2.56(1.75-7.6)$ & 3.20 & 16.00 & $0.78(0.54-1.83)$ & 0.001 \\
\hline
\end{tabular}

\section{Figures}

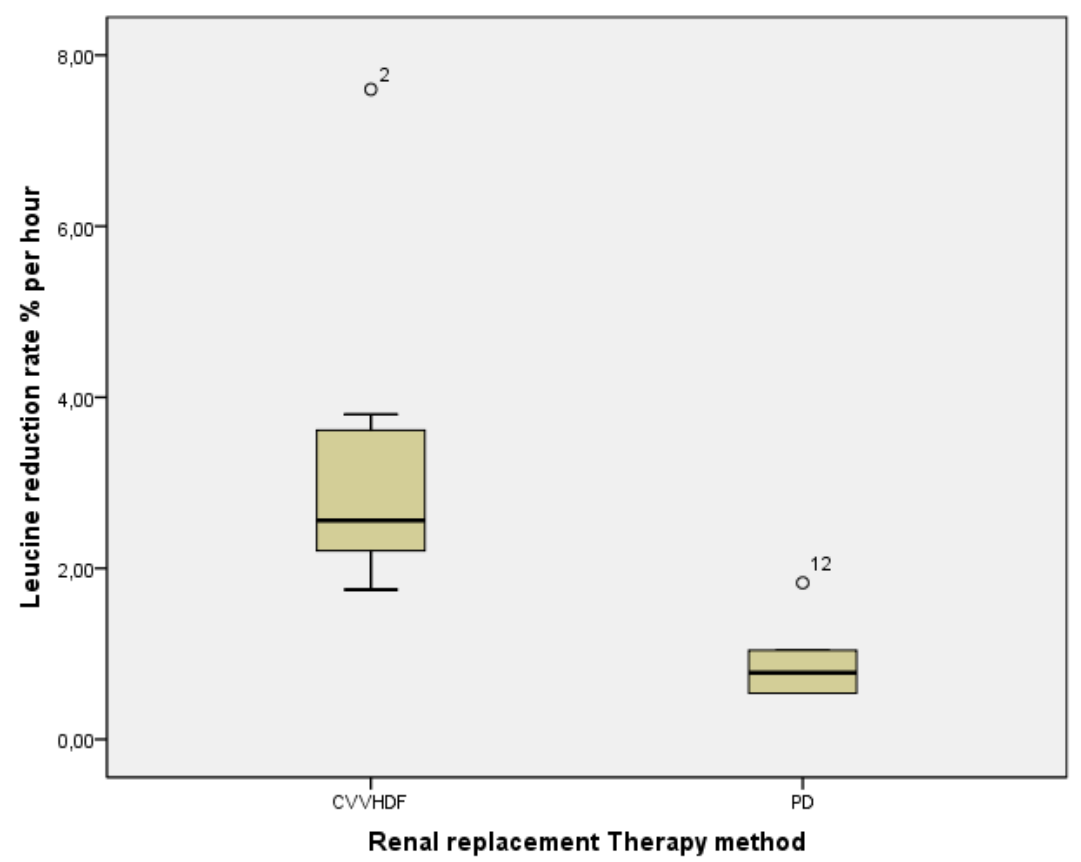

Figure 1

Leucine reduction rate \% per hour 


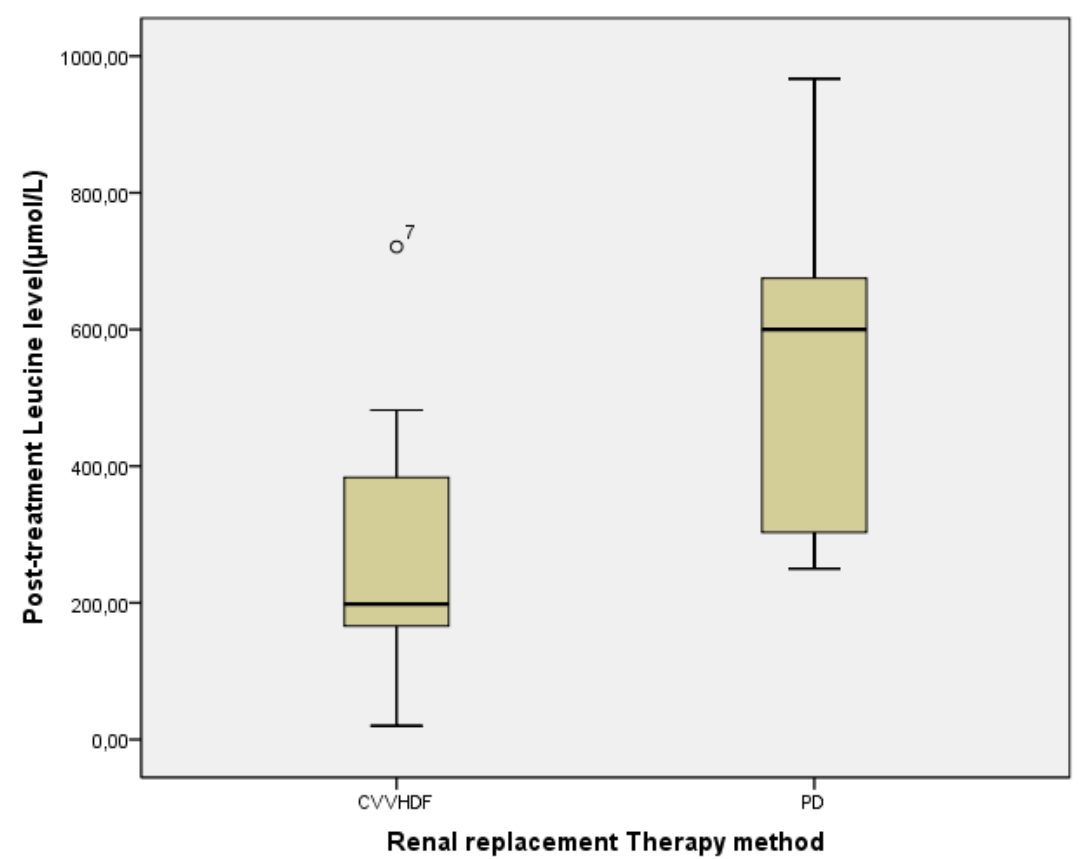

Figure 2

Posttreatment plasma leucine levels $(\mu \mathrm{mol} / \mathrm{L})$

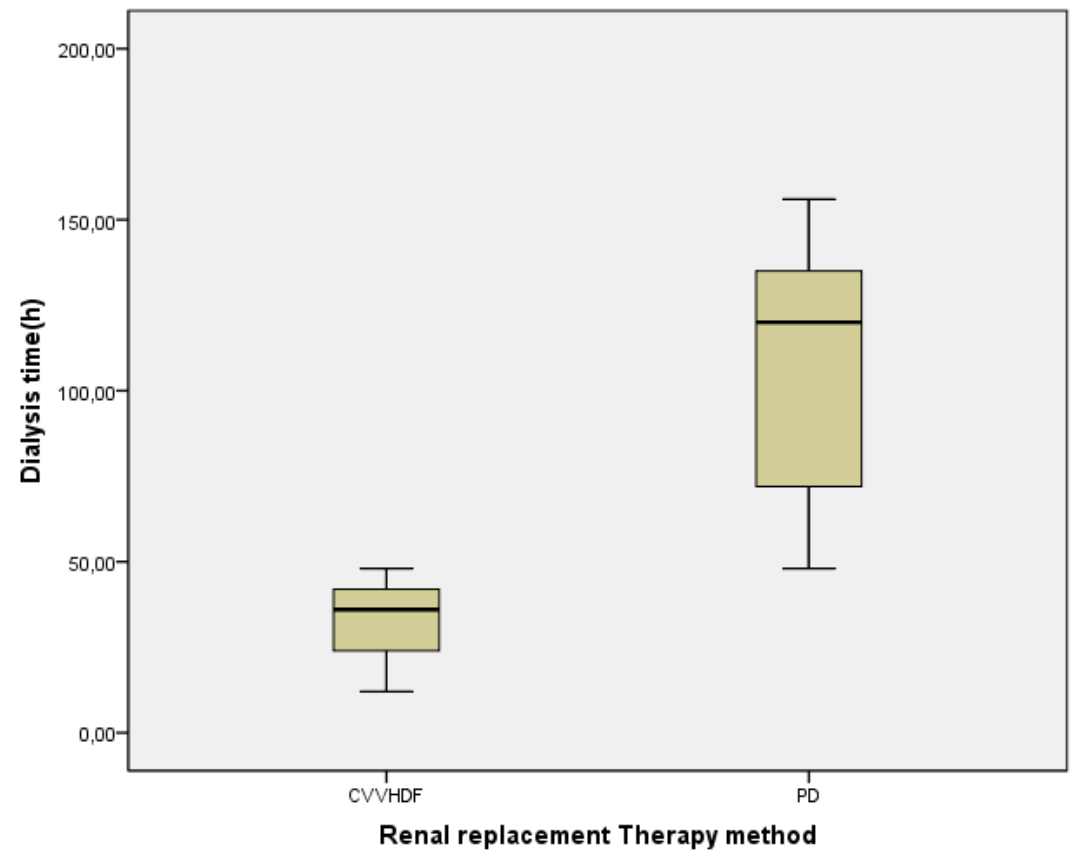

Figure 3

Dialysis time (hour) 